\title{
Insights Into Extracellular Vesicle/Exosome and miRNA Mediated Bi-Directional Communication During Porcine Pregnancy
}

\author{
Mallikarjun Bidarimath ${ }^{1}$, Harshavardhan Lingegowda ${ }^{2}$, Jessica E. Miller ${ }^{2}$, Madhuri Koti ${ }^{2,3}$ \\ and Chandrakant Tayade ${ }^{2 *}$
}

${ }^{1}$ Department of Pathobiological Sciences, School of Veterinary Medicine, Louisiana State University, Baton Rouge, LA, United States, ${ }^{2}$ Department Biomedical and Molecular Sciences, Queen's University, Kingston, ON, Canada, ${ }^{3}$ Department of Obstetrics and Gynecology, Queen's University, Kingston, ON, Canada

OPEN ACCESS

Edited by:

Dariusz Jan Skarzynski, Institute of Animal Reproduction and

Food Research (PAS), Poland

Reviewed by:

Aneta Andronowska,

Institute of Animal Reproduction and

Food Research (PAS), Poland

Hakhyun Ka,

Yonsei University, South Korea

${ }^{*}$ Correspondence:

Chandrakant Tayade

tayadec@queensu.ca

Specialty section:

This article was submitted to Animal Reproduction -

Theriogenology,

a section of the journal

Frontiers in Veterinary Science

Received: 15 January 2021

Accepted: 11 March 2021

Published: 15 April 2021

Citation:

Bidarimath $M$, Lingegowda $H$, Miller JE, Koti M and Tayade C (2021) Insights Into Extracellular

Vesicle/Exosome and miRNA Mediated Bi-Directional

Communication During

Porcine Pregnancy.

Front. Vet. Sci. 8:654064.

doi: 10.3389/fvets.2021.654064
Spontaneous fetal loss is one of the most important challenges that commercial pig industry is still facing in North America. Research over the decade provided significant insights into some of the associated mechanisms including uterine capacity, placental efficiency, deficits in vasculature, and immune-inflammatory alterations at the maternal-fetal interface. Pigs have unique epitheliochorial placentation where maternal and fetal layers lay in opposition without any invasion. This has provided researchers opportunities to accurately tease out some of the mechanisms associated with maternal-fetal interface adaptations to the constantly evolving needs of a developing conceptus. Another unique feature of porcine pregnancy is the conceptus derived recruitment of immune cells during the window of conceptus attachment. These immune cells in turn participate in pregnancy associated vascular changes and contribute toward tolerance to the semi-allogeneic fetus. However, the precise mechanism of how maternal-fetal cells communicate during the critical times in gestation is not fully understood. Recently, it has been established that bi-directional communication between fetal trophoblasts and maternal cells/tissues is mediated by extracellular vesicles (EVs) including exosomes. These EVs are detected in a variety of tissues and body fluids and their role has been described in modulating several physiological and pathological processes including vascularization, immune-modulation, and homeostasis. Recent literature also suggests that these EVs (exosomes) carry cargo (nucleic acids, protein, and lipids) as unique signatures associated with some of the pregnancy associated pathologies. In this review, we provide overview of important mechanisms in porcine pregnancy success and failure and summarize current knowledge about the unique cargo containing biomolecules in EVs. We also discuss how EVs (including exosomes) transfer their contents into other cells and regulate important biological pathways critical for pregnancy success.

Keywords: angiogenesis, cytokines, exosomes, fetal loss, immune cells, inflammation, trophoblasts 


\section{INTRODUCTION}

The pig industry around the world produces more than 100 million of pork annually and the value of U.S. and Canadian pork and pork products exports to the world reached a record $\$ 11$ billion (1). Due to their high productive and reproductive efficiencies, the pigs contribute to the lower cost of pork production $(2,3)$. An average of 23.6 piglets per year can be produced by a single sow (4). Therefore, the litter size remains the prime contributing factor for greater yield of pork production. The litter size per gestation can be influenced by several entities such as ovulation rate, fertilization rate, and establishment of pregnancy and conceptus development and survival until the term. Pigs are highly prolific livestock species due to their certain reproductive characters such as higher ovulation rate $(20-25$ oocytes per cycle) (4) and fertilization rate (95\%) (4-6). However, the litter size reduces to $10-13$ piglets per sow, by the time they reach full term (7). The huge gap between these parameters is likely explained by a phenomenon called as spontaneous fetal loss, which occurs in two waves (8). A $20-30 \%$ of the conceptus are lost during the peri-attachment [gestation day (gd) 12-20] period (8) and an additional loss of $10-15 \%$ occurs during mid to late gestation, reviewed by $(7,9,10)$. During early pregnancy, a delicate balance is absolutely critical between developing conceptus and the maternal immunomodulatory mechanisms (11). The porcine placentation is non-invasive, diffuse, epitheliochorial type, which is characterized by neither decidualization of the endometrium like in humans and mice nor invasion of fetal tissues into the endometrium, but instead both the compartments lie in close, yet firm adhesion $(12,13)$. Research over last decades has pointed out at several factors that are crucial to fetal development such as genetic makeup of the animal (14), nutrient intake (15), placental development and homeostasis $(16)$, uterine capacity $(14,17)$, deficits in placental vasculature (18), disease outbreaks (19), immune mechanisms (20), and environment $(21,22)$ that specifically cause fetal loss. A variation in conceptus elongation rate and embryonic growth in early gestation especially around the peri-attachment period greatly alters the uterine environment, and thus negatively influencing the conceptus growth resulting in less developed conceptuses or even fetal demise (8). A similar variation in growth of littermates during the mid and late gestation leads to unequal space acquisition within the uterine lumen. The fetuses with comparatively higher growth rate exceed their uterine space, which pushes and compresses adjacent slow growing littermates resulting in stress/hypoxia induced conceptus arrest $(8,23,24)$.

Successful porcine pregnancy is dependent on conceptus attachment and placental development, which requires a bidirectional communication between conceptus and endometrium. Previous studies have suggested many important factors that play a crucial role in pregnancy success. These factors include but not limited to conceptus-derived estrogen and growth factors (25), progesterone $(26,27)$, immune cells (18, 28-30), cytokines (18), chemokines $(31,32)$, miRNAs $(29,33)$, EVs including exosomes $(34,35)$, mRNA destabilizing factors (36), pro- and anti-angiogenic immune-related miRNAs $(29,34)$, and seminal fluid derived factors $(37-41)$. However, most of these published studies only associate findings with fetal loss and a more comprehensive understanding of cause and effect relationship is required. In this review, we provide overview of important mechanisms associated with successful pregnancy or failure. We also summarize how contents from fetal and maternal derived EVs (including exosomes) contribute to pregnancy associated physiological adaptations.

\section{IMMUNE MECHANISMS AT THE PORCINE MATERNAL-FETAL INTERFACE}

Pleiotropic glycoprotein molecules such as cytokines are secreted by a variety of immune and non-immune cells in the uterine microdomain. Cytokines regulate several pregnancy related mechanisms including inflammation $(42,43)$, angiogenesis (18), innate and adaptive immune responses and cell death (44). These processes particularly influence the elongation and attachment of growing conceptus, endometrial adaptation to paternally derived antigens, successful conceptus attachment and overall development. Research over the past few years has characterized the role of members of the transforming growth factor beta superfamily, interferons (especially IFN- $\gamma$ and IFN- $\delta$ ), and interleukins (IL-1A, IL-1B, IL-1B2, IL-6) (44-46). During gd 910 and gd 15-18, there is dramatic change in the endometrial expression of TNF $\alpha$, tumor necrosis factor alpha-inducible protein 6 (TNFAIP6), inter- $\alpha$-trypsin inhibitor heavy chains (ITIH), and IL-6 that regulate the extracellular matrix expansion. IFN- $\gamma$ is typically secreted around gd 12 and dramatically increases around gd $16(47,48)$. In our previous studies, the fetal loss during the peri-attachment period coincided with increased IFN- $\gamma$ expression, while its expression was unaltered during a second wave of fetal loss around mid-pregnancy (gd50) (49). The transient increase in IFN- $\gamma$ expression between gd12 and 15 influences the immune cell recruitment and differentiation at the maternal-fetal interface $(50,51)$. We observed increased expression of inflammatory cytokines such as TNF- $\alpha$, IL-1B, and IL-1 receptor at the conceptus attachment sites associated with arresting/dying conceptus during the peri-attachment period (49). These studies suggest that these pro-inflammatory cytokines initiated acute inflammatory response that results in the conceptus loss and resorption. Although counter argument of immune cell infiltration and their functional products, cytokines, are released to clear dying/dead conceptus cannot be fully ruled out. This adds to the complexity of cause and effect question associated with fetal loss.

Immune cell recruitment to the maternal-fetal interface in porcine pregnancy is largely driven by conceptus derived signals and set of specific chemokines and growth factors (52-54). Secreted by several immune cell types, chemokines are small signaling molecules predominantly involved in the recruitment and activation of circulating leukocytes to the sites of inflammation (55). During early pregnancy, a remodeling in the uterine microdomain happens at the sites of conceptus attachment. Therefore, the chemokines secreted by uterine epithelial cells, fibroblasts as well as resident immune cells would act to influence an increased extravasation and chemotaxis along 
the concentration gradient (54). However, a delicate balance is critical between a chemotaxis induced inflammatory processes and tissue homeostasis around the days of conceptus attachment and establishment of pregnancy.

Our previous research has explored these avenues by investigating the role of transcripts encoding decoy receptors, D6, duffy antigen receptor for chemokines (DARC) and chemocentryx decoy receptors (CCX-CKR). The mRNAs for decoy receptors (DARC and CCX-CKR) were dysregulated in the endometrium and chorioallantoic membrane; however, there was no difference in their expression at the protein level. A posttranscriptional and/or epigenetic modification of chemokines and their specific receptors, as well as action by proteolytic enzymes could explain these differences in expression during pregnancy (32). In another study, we investigated a distinct set of chemokines and their receptors that likely play a role in immune cell associated functions in laser microdissected endometrial lymphocytes, endometrium, and chorioallantoic membrane derived from both the arresting and healthy conceptus attachment sites. We demonstrated that lymphocytes residing in the arresting conceptus attachment sites had higher expression of CXCR3 and CCR5 mRNA, and there was greater expression of CXCL10, CCL5, CCR5, and CXCR3 mRNA in the endometrium around peri-attachment period ( $\operatorname{gd} 20)$. Recently, Han and colleagues examined the expression of CXCL12 and CXCR4 at the maternal-conceptus interface during pregnancy in pigs. This study reported the highest expression of CXCL12 on day 15 of pregnancy. Furthermore, CXCL12 protein expression was localized in endometrial epithelial cells, however, CXCR4 protein was detected in vascular endothelial cells, subepithelial stromal cells, and endometrial immune cells. CXCL12 increased the migration of cultured porcine trophectoderm cells and peripheral blood mononuclear cells as well as along with CXCR4 induced the migration of trophectoderm cells and T cells at the implantation in pigs. These experiments highlight role of CXCL12 in regulating trophoblast migration and $\mathrm{T}$ cell recruitment into the endometrium during implantation period in pigs (56). Recently, a study screened a broad range of chemokines (CCL2, CCL4, CCL5, CCL8, CXCL2, CXCL8, CXCL10, and CXCL12) and their receptors (CCR1, CCR2, CCR3, CCR5, CXCR2, CXCR3, and CXCR4) in luminal epithelial cells. This study suggests that CCL8 actively participates in embryo implantation and CXCL12 participates in endometrial receptivity and promotion of embryo attachment (57). Similarly, the same group screened the expression of same set of chemokines in endometrial stromal and endothelial cells and suggested that CCL2 modulates stromal cell function and CCL4 and CCL8 stimulate blood vessel development (58). These studies suggest that a further characterization of these chemokines and their specific receptors including decoy receptors may provide a better understanding of their role in immunomodulatory activity and overall function during conceptus attachment and subsequent development (31).

Previous studies in our laboratory and others have identified deficits in angiogenic stimuli that likely results in impaired vascular development at the maternal-fetal interface $(18,29,49$, 59). This is one of the important primary causes that leads to either stunted growth in surviving fetuses or fetal mortality during early stages of pregnancy. Various immune cell types have been evaluated for their crucial role during porcine pregnancy. Around the peri-attachment period (gd 12-15), the vascular remodeling of the endometrium coincides with infiltration of various innate and adaptive immune cells including natural killer cells, dendritic cells, macrophages, lymphocytes and plasma cells (60-62). The natural killer cells are generally detectable at gd 12 in pigs, which typically aggregate beneath the uterine luminal epithelium, around uterine glands, perivascular areas as well as randomly scattered throughout the uterine stroma $(60,61,63)$.

It is important to note that the conceptus attachment to the endometrium is critical for the recruitment of uterine natural killer (uNK) cells in pigs as the decidualization is not induced in these species. However, in case of humans, mice and rats, where decidualization occurs, presence of conceptus is not critical for uNK cell recruitment $(61,64)$. $\mathrm{T}$ cells and uNK cell mobilization to the sites of blastocyst attachment and placentation typically noticed between gd 1528 (65). However, their enrichment differs in various species. Compared to species with hemochorial placentation (human, mice), the uNK cell enrichment in the conceptus attachment sites of pigs is not pronounced, but only reaches about 3fold. The immunological response at the maternal-fetal interface especially in mice and humans are characterized by intrauterine immune suppression, non-classical MHC molecule expression by trophectoderm and immune-protective molecules including Fas ligand (CD95) expression by the trophoblast (66-68). The porcine placental cells do not express MHC class I molecules (swine leukocyte antigens [SLAs]) (69), however, the stromal cells and luminal epithelial cells express classical and nonclassical SLA class I molecules (SLA-1,-2,-3,-6,-7, and-8) as well as $\beta 2$-microglobulin (70). Primarily involved in antigen presentation, MHC class II molecules (SLA DQA) demonstrate a greater expression in subepithelial stromal cells and endothelial cells of the endometrium in response to conceptus-derived IFN- $\gamma$ during the window of conceptus attachment (71). The conceptus likely modulates SLA-DQA expression and hence indirectly influences the maternal immune system for its survival.

\section{microRNAs INVOLVED IN REGULATION OF ANGIOGENESIS AND IMMUNE CELL DEVELOPMENT}

The regulation of gene expression at the porcine maternal-fetal interface is controlled by several biomolecules at the genomic level. One of the most important implicated biomolecules are microRNAs (miRNAs), a class of small non-coding RNAs ( 18-22 nucleotide in length) that play a major role in RNA silencing and post-transcriptional gene regulation (72). MiRNAs negatively regulate translation either by deadenylating and destabilizing the mRNA or by repressing the translational machinery. miRNAs are primarily involved in regulating both physiological and pathological processes including but not limited to cellular proliferation and differentiation, homeostasis, inflammatory processes, and cell death $(72,73)$. 
Most mammalian miRNAs are highly conserved among species $(74,75)$ and regulate at least $70 \%$ of all the genes in their specific genome (76). Each miRNA can repress the expression of multiple target mRNA, while each mRNA target is regulated by many miRNAs, suggesting that the regulation of gene expression is highly complex.

Because of their unique expression pattern in both physiological and pathological processes, miRNAs are projected as biomarkers of both healthy pregnancy and associated disorders. In one study, a set of 17 miRNAs were identified in the porcine placenta samples obtained from pigs at gd 30 and 90. Differentially expressed 8 miRNAs between the two time points, such as let-7i, miR-106a, miR-17, miR-24, miR-92b, miR-125b, miR-20, and miR-27a were validated by stem-loop RT-PCR. Further bioinformatic analysis of mRNA targets and potential biological pathways indicated that these miRNAs are involved in regulation of cell growth, trophoblast differentiation, maintenance of adherence junctions and angiogenesis (77). miRNAs appear to follow a pattern of expression depending on the overall dynamics of cellular processes, that are typical of porcine pregnancy. Based on the temporal expression patterns, a study had identified 65 miRNAs in the endometrium to capture crucial stages of pregnancy such as conceptus attachment (gd 15), placental development (gd 26), and mid-gestation (gd 50) (78). These miRNAs appear to regulate the processes associated with embryo attachment, placental development and overall homeostatic mechanisms associated with pregnancy. This study further characterized the binding sites of two miRNAs, miR-181a and miR-181c in the transcripts of genes such as ITGB3, ESR1, and SPP1, which are proven to play a crucial role in embryo implantation (78).

Studies over the past decade have characterized several miRNAs that regulate various porcine reproductive and pregnancy associated processes, including oocyte and conceptus development $(35,79,80)$, implantation $(35,78)$, immune cell recruitment, and placental angiogenesis (29, 33), placental growth and function (77), and litter size (81-83). Specific examples include miRNA-29a that triggers the degradation of basement membrane and stromal matrix by interacting with LAMC1 (encodes laminin subunit gamma 1), COL1A2 (encodes collagen type 1 alpha, chain 2), and COL3A1 (encodes collagen type 3 alpha, chain 1). Further, miR-200 family and miR-205 shown to control the trophoblast epithelial cell adherens junctions by interacting with ZEB2 and CDH1. Similarly, miR-17-92 regulate trophoblast proliferation by interacting with HBP1 and ULK1 miRNAs (84). The miRNA synthesis and their transportation across the cellular compartments is also a highly regulated process. A set of 10 genes namely DGCR8, AGO3, AGO4, XPO5, AGO1, AGO2, DICER1, DROSHA, TNRC6A, and TARBP2 that code for proteins involved in miRNA synthesis and transport have been investigated for their role in the endometrium of pigs. Using bioinformatics approach, this study identified target transcripts, VEGF, IL-6R, LIF, and PTGS2, that play a crucial role in maternal-fetal communication (35). Similarly, a distinct set of genes that regulate miRNA synthesis and transport (DGCR8, TNRC6A, DROSHA, XPO5, DICER, AGO1 to-4, and TARBP2) as well as miRNAs such as
miR-140 were investigated in pregnant and cyclic endometria obtained on gd 12, 16, and 20 in pigs. The expression of DROSHA, XPO5, DICER1, TARBP, and AGO1 was altered by the reproductive status of animals. Overall, these studies suggest that the interaction between miRNAs and genes involved in miRNA synthesis and transport likely involved in the regulation of estrous cycle and initial stages of embryo attachment (79).

Studies from our group evaluated the expression of 236 miRNAs in endometrial specimens and fetal trophoblasts derived from both the healthy and growth arrested conceptus attachment sites at gd 20. We reported significantly higher expression of miR331-5p, 330-5p, 323, and 935, while miR-10a, 27a, 29c, and 374b$5 \mathrm{p}$ in the endometrial samples associated with healthy attachment site. These were one of the initial miRNA array-based studies to highlight the importance of miRNAs in the porcine pregnancy. Importantly, in this study, we found that the differentially expressed mRNAs indeed regulate many biological processes associated with pregnancy such as blood vessel development, nuclear transcription factor regulation, and extracellular matrix factors (85).

Due to the non-invasive superficial attachment, the epitheliochorial placentation in pigs enables us to easily isolate both maternal and fetal tissues to study molecular mechanisms without intermixing the compartments. Angiogenesis is one of the major mechanisms determines the success of implantation and growth of fetus. Therefore, our initial studies on immuneangiogenesis axis prompted us to explore miRNA regulation in recruited immune cells to the endometrium during pregnancy. Using laser capture microdissection, we isolated lymphocytes from the endometrium associated with both the arresting and healthy conceptus attachment sites and conducted targeted miRNA profiling on these immune cell subsets. Our major focus was to study miRNAs that are reported to be associated with immune cell development and overall pregnancy associated functions including angiogenesis. Interestingly, a distinct set of miRNAs such as miR-17P-5P, miR-18a, miR-19a, miR-150, and miR-296-5P were differentially expressed in the endometrial lymphocytes obtained from healthy conceptus attachment sites compared to their arresting counterparts. Further, there was significant differences in the expression of miR-17-5P, miR-20b, and $\mathrm{miR}-18 \mathrm{a}$ in the endometrium isolated during early pregnancy stages at gd20 (29). These studies provide concrete evidence into the role of miRNAs in the immune cell differentiation in the porcine endometrium and their expression levels changes depending on the pregnancy status. More importantly, this study also demonstrates that angiogenic miRNAs are enriched in the endometrial lymphocytes and can regulate immune cell promoted angiogenesis at the maternal-fetal interface to support developing conceptus (29).

\section{BIOGENESIS AND SECRETORY MECHANISM OF EXTRACELLULAR VESICLES}

Extracellular vesicles (EVs) is a general term used to describe membrane bound vesicles secreted by several cells for differing 
functions. Although previously thought to be exclusively intended for the secretion and elimination of waste, EVs contain coding and non-coding nucleic acids, lipids, and proteins, which are highly relevant for intercellular communication, homeostatic processes and also contribute to pathologies including those at the maternal fetal interface $(34,86,87)$. Although heterogeneric in size, composition, origin, and function, EVs are generally categorized into two groups: exosomes and microvesicles (MV). Exosomes range in size from 30 to $150 \mathrm{~nm}$ while MV range from $150 \mathrm{~nm}$ to $1 \mu \mathrm{m}$ in diameter. In addition to size, morphology [described as round or saucer shaped (88)] and specific markers are used for categorization. Due to significant controversy surrounding the proper categorization of EVs together with a rise in scientific publications in recent years, the International Society for Extracellular Vesicles have proposed specific guidelines and protocols to direct the nomenclature, isolation of pure EV preparations and proper categorization of EVs (89). Briefly, isolation techniques of EVs include differential ultracentrifugation, density gradient centrifugation, filtration, and size exclusion chromatography. Characterization to confirm size, morphology, and marker presence is conducted by immunoblotting, flow cytometry, transmission electron microscopy, or nanoparticle tracking analysis. Although one marker does not exclusively identify EVs, proteins such as tetraspanins (including CD9, CD63, and CD82), as well as other sorting complex proteins are used to identify EVs (in both exosomes and MV).

Biogenesis and secretion of exosomes compared to $\mathrm{MV}$ is different. MV are released via budding of the plasma membrane and are thought to be released faster, as the cargoes targeted by these are situated at the plasma membrane. Whereas, exosomes are first formed as intralumenal vesicles (ILVs) within multivesicular endosomes (MVEs) of the cell and secretion requires sorting of cargoes through endosomal-sorting-complexrequired-for-transport (ESCRT) dependent or independent pathways. Recent studies in the field have explored the possibility of sorting machineries, especially ESCRT complexes to be involved in decision making to target MVEs for either degradation or secretory pathway (90) through ALIX (ESCRT III associated complex) dependent mechanism (91). Similarly, another ESCRT complex associated protein (TSG101) has been studied by Villarroya-Beltri et al., where, a key posttranslational ubiquitin-like modification, ISGylation of TSG101 has been identified to be the probable signaling mechanisms that drives MVEs to fuse with lysosomes to induce degradation instead of secretion (92). Regardless of the outcomes, MVEs need to be transported continuously to either fuse with lysosomes or plasma membrane through general cellular transportation molecules such as actin, microtubule cytoskeleton, cortactin, RAB protein complexes and their effector molecules $(93,94)$. Studies in cancer cell lines have shown that actin cytoskeleton to be involved in the transportation and secretion of exosomes (94). Transportation of vesicles within the cells, including budding and fission of MVEs at the plasma membrane is tightly governed by GTPases-RAB protein family that consists of up to 60 members.
Even though the exact mechanism of action is not understood, members of RAB protein family such as RAB2B, RAB4, RAB5A, RAB7, RAB9A, RAB11, RAB27A, RAB27B, and RAB35 have been found to be involved specifically in endosome transport to plasma membrane and secretion of exosomes, as discussed elsewhere (95). Finally, fusion of MVEs to the plasma membrane is necessary to release ILVs as exosomes, which is thought to be primarily mediated by $\mathrm{N}$-ethylmaleimide-sensitive factor attachment protein receptors (SNAREs). SNARE protein complexes are made up of three to four subunits forming helices that are conventionally involved in exocytosis of lysosomes $(96,97)$. Recent developments in the field has identified a few proteins of SNARE family members namely, vesicle-associated membrane protein 7 (VAMP7), Synaptobrevin Homolog YKT6, syntaxin $1 \mathrm{~A}$ and syntaxin 5 to be crucial to facilitate the release of exosomes. Depending on the subtypes of MVEs, organism and cell type, diverse regulation of secretion by SNARE proteins have been identified in human embryonic kidney HEK293 cells (98), lung carcinoma A549 cells (99), Drosophila (98) (YKT6), and C. elegnas (syntaxin 1a and syntaxin 5) (100, 101). However, the exact stage where these molecules are recruited is yet to be identified. This limitation is mainly regarded to the technical approach as well as intracellular complexity of exosome release.

Interestingly, the release of EVs is an evolutionarily conserved process in both prokaryotes and eukaryotes and therefore EVs serve diverse biological functions, reviewed extensively here (102). As mentioned earlier, EVs including exosomes contain lipids, nucleic acids (mRNA, miRNA, DNA), enzymes, transcription factors and extracellular matrix proteins packaged by parental cells that exert drastic effects in the recipient cell (103). Conventional cell to cell communication occurs through surface protein interaction with neighboring cells, whereas hormones and cytokines are recruited to fulfill distant interactions (104). Considering the contents of exosome cargo, number of studies have centralized the approach toward understanding the molecular interactions between exosomes and recipient cells. Although the entire mechanism is not fully understood, it is known that exosomes are required to fuse with the plasma membrane, followed by signal transduction and internalization (endocytosis, phagocytosis, and micropinocytosis) with the target cells in order to deliver the cargo and establish intercellular communications. Known mechanism of action includes interaction with surface bound receptors, epigenetic modification via genetic material and activated receptor transfer to the target cell. Transmembrane proteins (integrins, tetraspanins) and extracellular matrices are primarily involved in binding exosomes to the target cells. Adhesion proteins such as intracellular adhesion molecules (ICAM) have been identified to interact during uptake with the integrins present on exosomes (105). Specific route of internalization is thought to be influenced by the content of molecules carried by exosomes. Studies in human pancreatic cancer cells have identified mutant KRAS gene to influence the exosomes to be internalized via micropinocytosis (106). Similarly, complexity of exosome action surrounding specific 
cell targeting is believed to be determined based on the cargo carried by exosomes.

\section{EXTRACELLULAR VESICLES IN PORCINE PREGNANCY}

A successful conceptus attachment to the endometrium and subsequent maintenance of pregnancy requires a proper communication between endometrium and conceptus (11). There are already several well-understood mechanisms of cellcell communication such as hormones, cytokines, and lipids that act in an autocrine and paracrine manner, intercellular nanotubules (107), direct adhesion between cell of origin and target cell, and membrane-bound microvesicles (108). Research over the past decade has provided critical evidence into intercellular communication via EVs (109). The EVs have been demonstrated to transfer information from the cell of origin to the recipient cells to regulate cellular activities (Figure 1). This information could be in the form of proteins, lipids, miRNAs, mRNAs, DNA and many other small molecules, and thus reflecting the physiological state of the originating cells $(110,111)$. However, the transfer of information could be two way, where the recipient cell can in turn stimulate/induce the originating cells in order to elicit the cellular signaling pathways $(112,113)$.

The bioactivity possessed by these EVs is distinct. Therefore, EVs have the ability to influence both physiological (110) and pathological processes (111). However, the precise mechanisms regulated by exosomes is difficult to understand, due to their complexity of cargo, abundance, cell of origin, biogenesis and secretory mechanisms, and extracellular environment as discussed in earlier section. Another important characteristic of the exosomes is their stability in the extracellular spaces due to their lipid bilayer containing cholesterol, ceramide, sphingomyelins and other detergent-resistant membrane molecules, which are likely derived from the originating cells (114). These unique features allow them to carry information without leaking into the extracellular spaces. Upon entering the recipient cell, the exosomes dissociate to release cargo, which may regulate gene expression and influence biological processes such as cell proliferation, differentiation, and migration. The exosomes have been demonstrated to be released by cells of the reproductive tissues such as endometrial (115), oviductal (116), and follicular cells (117) as well as bodily fluids such as saliva (118), blood plasma (119), milk (120), amniotic fluid (121), semen (122), urine (123), and uterine luminal fluid (35). The exosomes carried through different bodily fluids can selectively interact with target cells and deliver a diverse set of molecules to influence target cell activity suggesting that exosomes provide a highly regulated and complex mode of cellular communication.

Although there are many mechanisms of communication between conceptus and maternal endometrium, the documentary evidence is increasing exponentially about EVs/exosomes being the important mode of communication at the maternal-fetal interface. However, this is not a totally new concept as the discovery of small vesicles goes back to early 1990's, where multiple small vesicles have been shown at the porcine maternal-fetal interface on gd 16 via electron microscopy (12). Research in recent years have shown that EVs including exosomes released by placental cells can cross into maternal endometrium to deliver cargo containing biomolecules to the recipient cells.

It already known that the exosomes have the ability to transfer many important biomolecules such as mRNA and miRNAs to their respective target cells, in which mRNA can be directed toward translating into protein and miRNA can be utilized to fine tune mRNA expression or repress translation $(124,125)$. Exosomes carrying these biomolecules can attach to the surface of target cell (126) and can be internalized by recipient cells (127, 128). Chromosome 19 miRNA cluster generates more than 50 miRNAs and this cluster appear to modulate immune response in pregnancy. The immunomodulatory mechanism is essential especially in early pregnancy to help recently attached conceptus to grow and favorably modulate maternal immune response to paternal antigen. Interestingly, one study demonstrated a viral resistance in recipient cells that received miRNAs that were packaged within the human trophoblast-derived exosomes (129).

Another interesting concept is that MV and exosomes can be released in a time dependent manner as well as based on the physiological status. For example, the secretome released from placenta during first trimester of human pregnancy predominantly consisted of exosomes (130), while during the second trimester, the composition of the secretome changed predominantly to microvesicles and also their number increased as the pregnancy advanced to term $(131,132)$. Similarly, the function regulated by these ever-changing components of microvesicles and exosomes also differs greatly depending on the stage of pregnancy. For example, the exosomes released during early human pregnancy contain HLA-G (MHC I G), that help in enabling maternal immune tolerance toward recently attached conceptus carrying paternal antigens (130). Furthermore, MV released by syncytiotrophoblasts induce proinflammatory activity, which is essential around the stages of pregnancy establishment (133). However, these dynamic variations in the components of secretome need to be investigated in pigs to understand how trophoblast derived EVs modulate maternal adaptions to pregnancy given the noninvasive type of placentation.

EVs have been shown to perform a variety of pregnancy associated functions that most often reflect the constituents of its cargo. Conceptus attachment sites in pigs undergo dramatic changes both during successful and abortive pregnancy. For example, conceptus attachment sites associated with arresting embryo undergo an acute inflammatory process to enable resorption without affecting the adjacent littermate. Apoptosis can also get elicited in the conceptuses to remove or replenish the unnecessary cells. This mechanism of programmed cell death has been reported in many reproductive tissues such as uterine epithelium (134). Human placenta derived exosomes have been shown to carry Fas ligand and TRAIL molecules and induce apoptosis in activated immune cells and thus providing maternal immune tolerance toward developing fetus (135). Similarly, a regulatory protein such as bcl-2-like protein 15 (BCL2L15) has 


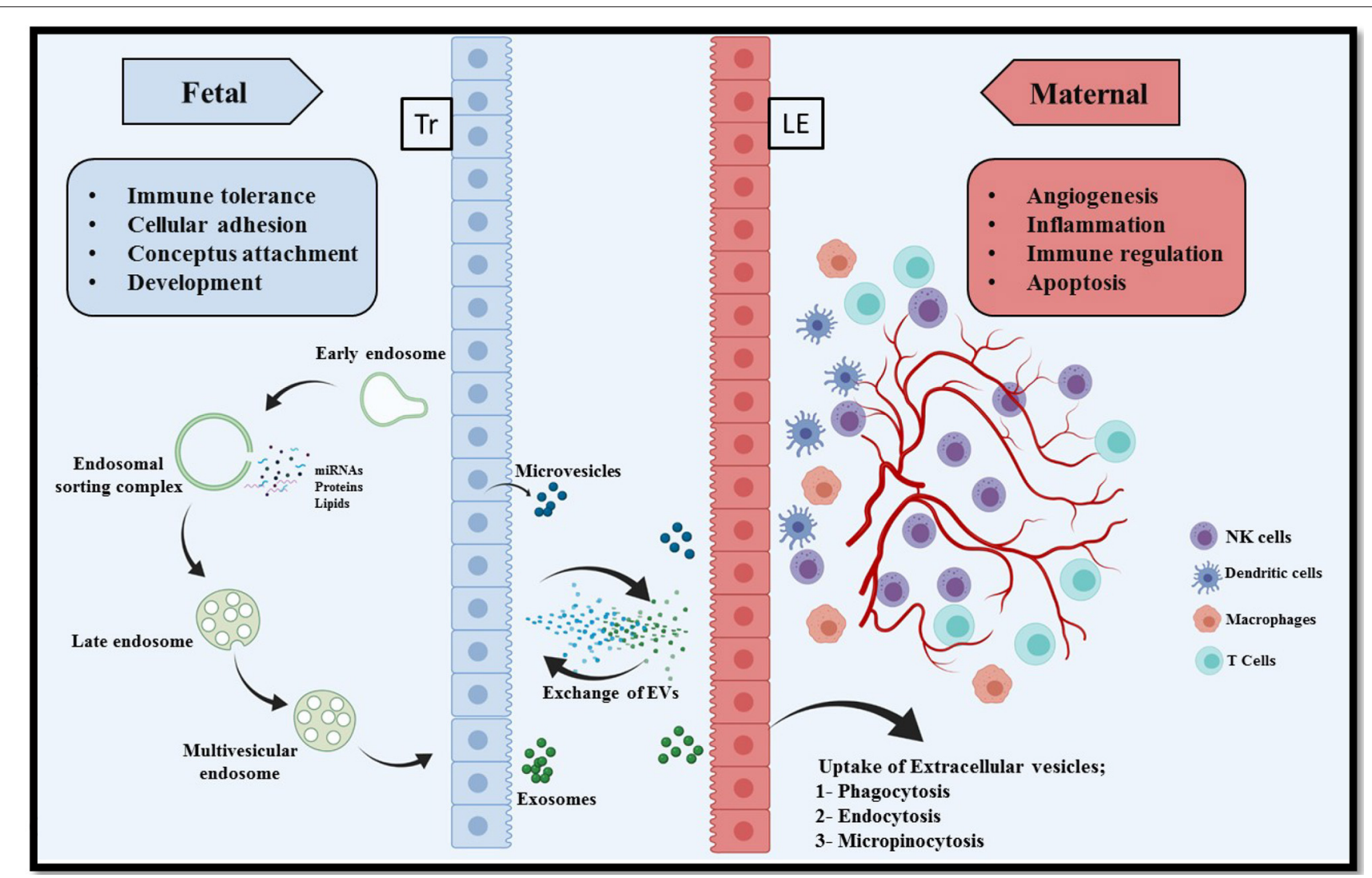

FIGURE 1 | Extracellular vesicle mediated bi-directional communication at the porcine maternal fetal interface. In epitheliochorial placentation in pigs, fetal trophoblasts (Tr) lay in simple apposition with maternal endometrial luminal epithelium (LE). Extracellular vesicles comprising microvesicles and exosomes are a heterogeneous group of cell-derived membranous structures originated from either endosomal system (microvesicles) or shed from the plasma membranes (exosomes). The unique cargo of these EVs contain biomolecules (nucleic acid, proteins, and lipids). These EVs can be internalized by multiple pathways including phagocytosis, endocytosis, pinocytosis, or can remain bound to the cell surface depending on the cell type. Interaction of EVs with recipient cells modulate several critical pregnancy associated processes, for example, conceptus attachment, development, immune tolerance on the fetal side and angiogenesis, inflammation, and apoptosis on the maternal side.

been reported in ovine uterine EVs during the periattachment period, gd17 (136). Another study in cows demonstrated that EVs obtained from gd 17 induced greater expression of apoptoticrelated genes, BAX, TNFA, TP53, and CASP3 in primary endometrial epithelial cells (137). These findings indicate a crucial role for EVs in apoptotic removal of immune cells (immunomodulation) and endometrial epithelial cells to help in uterine remodeling for conceptus attachment.

A recent study has isolated and characterized the EVs in porcine uterine flushing fluid collected on gd10, 13, and 18. Contents of these EVs especially small RNAs were comprehensively profiled through small RNA sequencing analysis. The cargo consisted of 152 known miRNAs, 43 novel miRNAs, 6248 known Piwi-interacting RNAs (piRNAs), and 110 novel piRNAs were identified. Subsequent bioinformatics analysis revealed that the miRNA enriched in the EVs involved in important pregnancy associated pathways such as immunomodulation, endometrial receptivity, implantation and embryo development. These studies add to the miRNA repository as well as serve as a resource to further investigate crosstalk at the maternal-fetal interface (138). As integrin family proteins play an important role in embryo implantation, previous study demonstrated that EVs in the bovine uterine flushings isolated on $\operatorname{gd} 20$ and 22 were able to upregulate VCAM1 expression in endometrial epithelial cells (139). Similarly, a study involving exosomes from estrogen or progesterone treated human endometrial epithelial cells contained several members of integrin family. The integrins are crucial for exosome docking to target cells and regulate trophoblast adhesion to the endometrium (140). EVs isolated from uterine lumen flushings on gd12, 14, and 16 reported to contain miR-26a and miR$125 \mathrm{~b}$ and among these miRNAs, miR-125b directly regulated expression of genes that play role in attachment and embryo development in pigs (35). These studies support the notion that EVs can influence conceptus attachment and adhesion to the endometrium. However, given fundamental differences in the placentation between human, mice and pigs, a pig centric studies are warranted to investigate mechanisms by which the biomolecules packaged in EVS/exosomes regulate porcine pregnancy related functions. 
Placental angiogenesis is an important pregnancy related processes crucial for conceptus development and remodeling of endometrium especially in early pregnancy to provide nutrients to the fetus. The placentation in pig typically initiates gd 15-20, which involves an abrupt change in endometrial microenvironment and associated biological processes including angiogenesis (141, 142). Studies from our laboratory have investigated angiogenesis at the porcine maternal-fetal interface and recently, we demonstrated that both the porcine trophectoderm cells, representing fetal tissues and endothelial cells, representing maternal tissues release EVs (34). Furthermore, these experiments demonstrate that EVs derived from porcine trophectoderm cells can stimulate endothelial cell proliferation, suggesting that EVs can stimulate angiogenesis. We have shown that EVs derived from porcine trophoectoderm cells (PTR2) contains several important proteins and miRNAs such as miR-126-5P, miR296-5P, miR-16, and miR-17-5P that have been shown to play a major role in angiogenesis (34). miR-150 packaged within exosomes derived from porcine umbilical cord blood stimulated proliferation, migration, and tube formation of umbilical vein endothelial cells. These studies indicate that EVs especially those derived from fetal tissues have the ability to stimulate endometrial angiogenesis and thus, support the idea that an angiogenic deficit at the maternal-fetal interface can be therapeutically targeted by designer EVs and prevent subsequent conceptus loss.

The development of immunological tolerance against semiallogeneic fetus is a crucial event in the pregnancy success. Since fetal allografts carry paternal antigens, the maternal immune system should reprogram itself to not to recognize fetal antigens and elicit an immune response. EVs have been reported to modulate maternal immune response toward the newly attaching conceptus (143). Depending on the nature of cargo and also type of receptors present on their membrane, EVs are able to modulate the immune response at the maternal-fetal interface. Bovine EVs obtained from gd20, were able to downregulate expression of immune-related genes in endometrial epithelial cells immediately after the conceptus attachment is initiated (144). Zhao et al. reported in bovine pregnancy that bta-miR-98 as a likely maternal immune system regulator based on the miRNA profiles of EVs combined with bioinformatic analysis. Similarly, miRNA499 was reported to play a role in regulation of local inflammation at the bovine maternal-fetal interface by inhibiting NF-kB signaling. Further, disruption of miR-499 results in increased risk of pregnancy failure due to severe local inflammatory process, placental resorption in early pregnancy or even fetal growth restriction (87). These studies suggest that miRNA cargo present in the EVs can modulate immune response, ultimately, helping to achieve immune tolerance during early pregnancy. Although, our previous studies in pigs have pointed out a distinct set of miRNAs that may have immunomodulatory effect on the maternal immune system, more mechanistic in vivo evidence is needed to exploit the idea that miRNA loaded EVs can be used to potentially reduce spontaneous fetal loss in pigs in future.

\section{EXTRACELLULAR VESICLES IN SELECTIVE REPRODUCTIVE DISORDERS IN PIGS}

Extracellular vesicles in porcine pregnancy: Early pregnancy diagnosis or detecting early embryonic mortality could substantially improve reproductive efficiency in pigs and overall improve the economy of swine industry. Failure to conceive after insemination or undetected pregnancy at an early stage in pigs could result in severe economic loss. While there are many well-established techniques currently available, miRNAs and miRNAs packaged within the exosomes could be another important tool to be used as the earliest possible (before 25 days after fertilization) biomarkers of pregnancy (145). Zhou and colleagues profiled exosomes obtained from serum samples at days 9, 12, 15 from pregnant and non-pregnant pigs. They concluded that miR-92b-3p and miR-17-5p could be identified in the serum exosomes as earlier as day 9 of pregnancy and hence could be used as biomarkers of early pregnancy (145).

Interestingly, in one of our previous studies miR-17-5p was one of highly enriched miRNA present in the porcine trophectoderm cells, derived from day 12 of pregnancy, and porcine endothelial cells as well as exosomes released by these two cell types (34). miR-17-5p is involved in regulating many physiological and pathological processes including cell proliferation, apoptosis, and most importantly angiogenesis. In addition, the genes targeted by miR-17-5p are reported to be involved in important signaling pathways including MAPK, PI3K-Akt, and TGF- $\beta$. Similarly, a study involving cattle identified 27 circulating EV-derived miRNAs isolated from serum that were significantly increased on gd 17 embryonic mortality compared to pregnant cattle. Furthermore, a specific miRNAs such as miR-25, miR-16b, and miR3596 were differentially expressed on gestation days 17 and 24, reflecting the pregnancy status (146). In another study, a set of 27 miRNAs packaged within EVs from maternal blood were found to be in lower abundance in somatic cell nuclear transfer-derived bovine embryonic loss group that failed to reach term. Additionally, the predicted target genes of these 27 miRNAs were found to be associated with critical biological processes such as cell proliferation, apoptosis, and angiogenesis (147).

Role of extracellular vesicles in porcine reproductive and respiratory syndrome pathogenesis: EVs have been shown to play a role in diseases affecting reproductive organs in pigs. Porcine reproductive and respiratory syndrome (PRRS) is one of the important diseases affecting reproductive organs in pigs and causes a heavy economic loss to pork industry. It is characterized by reproductive failures in sows and respiratory syndrome in pigs of all ages (148). An emerging evidence indicates that exosomes released by cells infected by some viruses selectively package viral genetic material, viral proteins, or virions to transmit to neighboring healthy/uninfected cells (149). Purified exosomes isolated from PRRS virus infected cells contain viral genomic RNA and partial viral proteins. These exosomes loaded with viral components can deliver their contents to both PRRS virus susceptible and non-susceptible cells, indicating a viral 
transmission via exosomes while evading the host immune response (150).

Exosomes can serve as small RNA transfer vehicles and act as effective therapeutic tools. Zhu and colleagues conducted a study to target two key receptors, Sialoadhesin (Sn) and CD163 for PRRS virus infection of porcine alveolar macrophages. They designed artificial miRNAs that can directly target Sn and CD163 as PRRS virus enters the target cells via receptor-mediated endocytosis. They generated two recombinant adenoviruses expressing the effective artificial miRNAs. It was observed that sequence-specific artificial miRNAs were expressed adequately and released from recombinant adenovirus transduced pig cells via exosomes. Overall, PRRSV infection of pulmonary alveolar macrophages was inhibited by transduction of two artificial miRNA expressing recombinant adenoviruses and or treatment with two artificial miRNAs packaged within the exosomes. This study suggest that exosomes can be utilized to effectively treat infectious diseases such as PRRS (151). Another study by the same group, used exosome mediated transfer of artificial miRNA targeting the 3' untranslated region of PRRSV. They generated a recombinant adenovirus expressing the artificial miRNA that can target 3' untranslated region of PRRSV and further concluded that exosomes derived from porcine cells can be utilized as miRNA cargo and miRNAs delivered via exosomes effectively elicited anti-viral effects against different PRRSV strains (152). Montaner-Tarbes et al. isolated serum-derived exosomes from naïve animals, from PRRSV viremic animals and from animals recovered from PRRSV infection and already free of viruses (non-viremic). Their experiments suggest that the serum-derived exosomes contain antigenic viral-proteins, which could be used as a novel vaccine strategy against PRRSV infection (149). Further this group conducted a targeted-pig trial on safety and immunogenicity of serum derived EVs containing viral proteins and concluded that this could be an effective vaccine strategy (153).

\section{SUMMARY AND CONCLUSION}

Co-ordinated interactions between maternal endometrium and fetal trophoblasts at the highly dynamic interface is critical to ensure pregnancy success. In epitheliochorial placentation seen in pigs, the fetal trophoblasts lie in simple opposition with luminal epithelial cells of the endometrium but there is no invasion. The significant alterations in the uterine stroma as seen in other species such as human and mice is also lacking in pigs except localized branching of new blood vessels to support the needs of a growing conceptus. We and others have shown that the conceptus mediates the recruitment of immune cells

\section{REFERENCES}

1. United states Department of Agriculture, Foreign Agriculture Service. US Pork Hogs. (2019). Available online at: https://www.fas.usda.gov/ commodities/pork-and-hogs (accessed March 26, 2021).

2. Secco C, Luz LM da, Pinheiro E, de Francisco AC, Puglieri FN, Piekarski CM, et al. Circular economy in the pig farming that adopt a specialized phenotype and these immune cells contribute to and regulate angiogenesis at the porcine maternalfetal interface. It is important to recognize that because of the non-invasive placentation in pigs, trophoblasts do not physically interact with maternal-immune cells. In fact, trophoblasts in contact with luminal epithelium lacks SLA class I and II molecules and therefore avoid recognition by the maternalimmune cells. Maternal-immune cells predominantly NK cells and $\mathrm{T}$ cells are recruited around gd-12-15 at the maternal-fetal interface by conceptus mediated signals as well as specific sets of chemokines. The pro-inflammatory microenvironment and chemokine gradient is regulated by chemokine decoy receptors such as D6 and DARC. Recent evidence indicate that immune cell differentiation and function is also regulated by specific sets of miRNAs. Indeed, miRNAs are involved in modulating several physiological, homeostatic, and pathological processes including vascularization and inflammation. Several reports also indicate suitability of unique miRNA signatures in body fluids as predictors of health and disease.

The paradox of bi-directional communication between maternal and fetal compartments can be better explained by extracellular vesicle mediated inter-cellular cross talk, especially in species with epitheliochorial placentation where physical interactions between trophoblast and maternal immune cells is limited. The EV cargo containing genomic DNA fragments, RNAs, mRNAs, miRNAs, proteins, and lipids are specifically packaged and can be traced back to the cell of origin. The EV cargo contents are also influenced by the localized microenvironment cues and are involved in embryo implantation, placentation, pregnancy maintenance, and pregnancy associated disorders. With the advent of newer sequencing technologies and bioinformatics machine learning tools, the contents of EVs and their utility in understanding physiological changes in pregnancy and spontaneous fetal loss will be of immense value in future.

\section{AUTHOR CONTRIBUTIONS}

$\mathrm{MB}, \mathrm{MK}$, and CT conceived ideas and associated themes. HL and JM contributed sections of the manuscript. MB, HL, JM, MK, and CT wrote and edited manuscript. CT provided research funding and oversight. All authors contributed to the article and approved the submitted version.

\section{FUNDING}

This research was supported with funds from Natural Sciences and Engineering Research Council of Canada (Grant No. 388772). 
Anim Reprod Sci. (2005) 85:301-16. doi: 10.1016/j.anireprosci.2004. 05.019

5. Youngs CR, Christenson LK, Ford SP. Investigations into the control of litter size in swine: III. A reciprocal embryo transfer study of early conceptus development. J Anim Sci. (1994) 72:725-31. doi: 10.2527/1994.723725x

6. Anderson LH, Christenson LK, Christenson RK, Ford SP. Investigations into the control of litter size in swine: II. Comparisons of morphological and functional embryonic diversity between Chinese and American breeds. J Anim Sci. (1993) 71:1566-71. doi: 10.2527/1993.7161566x

7. Geisert RD, Schmitt RaM. Early embryonic survival in the pig: can it be improved? J Anim Sci. (2002) 80:E5465. doi: $10.2527 /$ animalsci2002.0021881200800ES10009x

8. Pope WF. Uterine asynchrony: a cause of embryonic loss. Biol Reprod. (1988) 39:999-1003. doi: 10.1095/biolreprod39.5.999

9. Ross JW, Ashworth MD, Stein DR, Couture OP, Tuggle CK, Geisert RD. Identification of differential gene expression during porcine conceptus rapid trophoblastic elongation and attachment to uterine luminal epithelium. Physiol Genom. (2009) 36:140-8. doi: 10.1152/physiolgenomics.00022.2008

10. Stroband HW, Van der Lende T. Embryonic and uterine development during early pregnancy in pigs. J Reprod Fertil. (1990) 40:261-77.

11. Bazer FW, Johnson GA. Pig blastocyst-uterine interactions. Differentiation. (2014) 87:52-65. doi: 10.1016/j.diff.2013.11.005

12. Keys JL, King GJ. Microscopic examination of porcine conceptus-maternal interface between days 10 and 19 of pregnancy. Am J Anat. (1990) 188:22138. doi: 10.1002/aja.1001880302

13. Enders AC, Blankenship TN. Comparative placental structure. Adv Drug Deliv Rev. (1999) 38:3-15. doi: 10.1016/S0169-409X(99)00003-4

14. Ford SP. Embryonic and fetal development in different genotypes in pigs. $J$ Reprod Fertil. (1997) 52:165-76.

15. Foxcroft GR, Dixon WT, Dyck MK, Novak S, Harding JCS, Almeida FCRL. Prenatal programming of postnatal development in the pig. Soc Reprod Fertil Suppl. (2009) 66:213-31. doi: 10.1530/biosciprocs.18.0028

16. Miles JR, Freking BA, Blomberg LA, Vallet JL, Zuelke KA. Conceptus development during blastocyst elongation in lines of pigs selected for increased uterine capacity or ovulation rate. J Anim Sci. (2008) 86:212634. doi: $10.2527 /$ jas.2008-1066

17. Freking BA, Leymaster KA, Vallet JL, Christenson RK. Number of fetuses and conceptus growth throughout gestation in lines of pigs selected for ovulation rate or uterine capacity. J Anim Sci. (2007) 85:2093103. doi: $10.2527 /$ jas.2006-766

18. Tayade C, Fang Y, Hilchie D, Croy BA. Lymphocyte contributions to altered endometrial angiogenesis during early and midgestation fetal loss. J Leukoc Biol. (2007) 82:877-86. doi: 10.1189/jlb.0507330

19. Pogranichniy RM, Schwartz KJ, Yoon KJ. Isolation of a novel viral agent associated with porcine reproductive and neurological syndrome and reproduction of the disease. Vet Microbiol. (2008) 131:35-46. doi: 10.1016/j.vetmic.2008.02.026

20. Linton NF, Wessels JM, Cnossen Sa, Croy BA, Tayade C. Immunological mechanisms affecting angiogenesis and their relation to porcine pregnancy success. Immunol Invest. (2008) 37:611-29. doi: 10.1080/08820130802191540

21. Hansen PJ. Effects of heat stress on mammalian reproduction. Philos Trans R Soc B Biol Sci. (2009) 364:3341-50. doi: 10.1098/rstb.2009. 0131

22. Morrow-Tesch JL, McGlone JJ, Salak-Johnson JL. Heat and social stress effects on pig immune measures. J Anim Sci. (1994) 72:2599609. doi: 10.2527/1994.72102599x

23. Wu MC, Hentzel MD, Dziuk PJ. Relationships between uterine length and number of fetuses and prenatal mortality in pigs. J Anim Sci. (1987) 65:762-70. doi: 10.2527/jas1987.653762x

24. Wilson ME, Biensen NJ, Ford SP. Novel insight into the control of litter size in pigs, using placental efficiency as a selection tool. J Anim Sci. (1999) 77:1654-8. doi: 10.2527/1999.7771654x

25. Bazer FW. Pregnancy recognition signaling mechanisms in ruminants and pigs. J Anim Sci Biotechnol. (2013) 4:23. doi: 10.1186/2049-1891-4-23

26. Spencer TE, Burghardt RC, Johnson GA, Bazer FW. Conceptus signals for establishment and maintenance of pregnancy. Anim Reprod Sci. (2004) 82-3:537-50. doi: 10.1016/j.anireprosci.2004.04.014
27. Spencer TE, Johnson GA, Burghardt RC, Bazer FW. Progesterone and placental hormone actions on the uterus: insights from domestic animals. Biol Reprod. (2004) 71:2-10. doi: 10.1095/biolreprod.103.024133

28. Croy BA, Wessels J, Linton N, Tayade C. Comparison of immune cell recruitment and function in endometrium during development of epitheliochorial (pig) and hemochorial (mouse and human) placentas. Placenta. (2009) 30(Suppl.A):26-31. doi: 10.1016/j.placenta.2008.09.019

29. Bidarimath M, Edwards AKAK, Wessels JMJM, Khalaj K, Kridli RTRT, Tayade C. Distinct microRNA expression in endometrial lymphocytes, endometrium, and trophoblast during spontaneous porcine fetal loss. $J$ Reprod Immunol. (2015) 107:64-79. doi: 10.1016/j.jri.2014.11.004

30. Linton NF, Wessels JM, Cnossen Sa, van den Heuvel MJ, Croy BA, Tayade C. Angiogenic DC-SIGN(+) cells are present at the attachment sites of epitheliochorial placentae. Immunol Cell Biol. (2010) 88:6371. doi: $10.1038 /$ icb.2009.62

31. Bidarimath M, Khalaj K, Kridli RTRT, Wessels JMJM, Koti M, Tayade C. Altered expression of chemokines and their receptors at porcine maternalfetal interface during early and mid-gestational fetal loss. Cell Tissue Res. (2016) 366:747-61. doi: 10.1007/s00441-016-2470-2

32. Wessels JM, Linton NF, van den Heuvel MJ, Cnossen Sa, Edwards AK, Croy BA, et al. Expression of chemokine decoy receptors and their ligands at the porcine maternal-fetal interface. Immunol Cell Biol. (2011) 89:30413. doi: $10.1038 /$ icb. 2010.95

33. Bidarimath $\mathrm{M}$, Khalaj K, Wessels JMJM, Tayade C. MicroRNAs, immune cells and pregnancy. Cell Mol Immunol. (2014) 11:538-47. doi: 10.1038/cmi.2014.45

34. Bidarimath M, Khalaj K, Kridli RTRT, Kan FWKFWK, Koti M, Tayade C. Extracellular vesicle mediated intercellular communication at the porcine maternal-fetal interface: a new paradigm for conceptus-endometrial crosstalk. Sci Rep. (2017) 7:40476. doi: 10.1038/srep40476

35. Krawczynski K, Najmula J, Bauersachs S, Kaczmarek MM. MicroRNAome of porcine conceptuses and trophoblasts: expression profile of microRNAs and their potential to regulate genes crucial for establishment of pregnancy. Biol Reprod. (2015) 92:21. doi: 10.1095/biolreprod.114.123588

36. Khalaj K, Wessels JMJM, Kridli RTRT, Bidarimath M, Lamarre J, Tayade C. mRNA destabilizing factors: tristetraprolin expression at the porcine maternal-fetal interface. Am J Reprod Immunol. (2015) 73:40216. doi: $10.1111 /$ aji. 12347

37. Piehl LL, Fischman ML, Hellman U, Cisale H, Miranda PV. Boar seminal plasma exosomes: effect on sperm function and protein identification by sequencing. Theriogenology. (2013) 79:1071-82. doi: 10.1016/j.theriogenology.2013.01.028

38. Katila T. Post-mating inflammatory responses of the uterus. Reprod Domest Anim. (2012) 47:31-41. doi: 10.1111/j.1439-0531.2012.02120.x

39. Bischof RJ, Brandon MR, Lee C-S. Cellular immune responses in the pig uterus during pregnancy. J Reprod Immunol. (1995) 29:16178. doi: 10.1016/0165-0378(95)00935-E

40. O’Leary S, Jasper MJ, Warnes GM, Armstrong DT, Robertson SA. Seminal plasma regulates endometrial cytokine expression, leukocyte recruitment and embryo development in the pig. Reproduction. (2004) 128:23747. doi: 10.1530/rep.1.00160

41. Jalali BM, Kitewska A, Wasielak M, Bodek G, Bogacki M. Effects of seminal plasma and the presence of a conceptus on regulation of lymphocytecytokine network in porcine endometrium. Mol Reprod Dev. (2014) 81:27081. doi: $10.1002 / \mathrm{mrd} .22297$

42. Murphy SP, Tayade C, Ashkar AA, Hatta K, Zhang J, Croy BA. Interferon gamma in successful pregnancies. Biol Reprod. (2009) 80:84859. doi: 10.1095/biolreprod.108.073353

43. Garlanda C, Maina V, Martinez de la Torre Y, Nebuloni M, Locati M. Inflammatory reaction and implantation: the new entries PTX3 and D6. Placenta. (2008) 29(Suppl.B):129-34. doi: 10.1016/j.placenta.2008.06.008

44. Geisert RD, Lucy MC, Whyte JJ, Ross JW, Mathew DJ. Cytokines from the pig conceptus: roles in conceptus development in pigs. J Anim Sci Biotechnol. (2014) 5:51. doi: 10.1186/2049-189 $1-5-51$

45. Mathew DJ, Lucy MC, Geisert DR. Interleukins, interferons, and establishment of pregnancy in pigs. Reproduction. (2016) 151:R11122. doi: 10.1530/REP-16-0047 
46. Ross JW, Malayer JR, Ritchey JW, Geisert RD. Characterization of the interleukin-1beta system during porcine trophoblastic elongation and early placental attachment. Biol Reprod. (2003) 69:1251-9. doi: 10.1095/biolreprod.103.015842

47. Bazer FW, Burghardt RC, Johnson GA, Spencer TE, Wu G. Interferons and progesterone for establishment and maintenance of pregnancy: interactions among novel cell signaling pathways. Reprod Biol. (2008) 8:179211. doi: 10.1016/S1642-431X(12)60012-6

48. Bazer FW, Song G, Kim J, Dunlap Ka, Satterfield M, Johnson Ga, et al. Uterine biology in pigs and sheep. J Anim Sci Biotechnol. (2012) 3:23. doi: 10.1186/2049-1891-3-23

49. Tayade C, Black GP, Fang Y, Croy BA. Differential gene expression in endometrium, endometrial lymphocytes, and trophoblasts during successful and abortive embryo implantation. J Immunol. (2006) 176:148-56. doi: 10.4049/jimmunol.176.1.148

50. Roberts RM, Chen Y, Ezashi T, Walker AM. Interferons and the maternalconceptus dialog in mammals. Semin Cell Dev Biol. (2008) 19:1707. doi: 10.1016/j.semcdb.2007.10.007

51. La Bonnardiere C, Martinat-Botte F, Terqui M, Lefevre F, Zouari K, Martal $\mathrm{J}$, et al. Production of two species of interferon by Large White and Meishan pig conceptuses during the peri-attachment period. J Reprod Fertil. (1991) 91:469-78. doi: 10.1530/jrf.0.0910469

52. Wessels JM, Linton NF, Croy BA, Tayade C, Croy AB, Tayade C. A review of molecular contrasts between arresting and viable porcine attachment sites. Am J Reprod Immunol. (2007) 58:470-80. doi: 10.1111/j.1600-0897.2007.00534.x

53. Du M-R, Wang S-C, Li D-J. The integrative roles of chemokines at the maternal-fetal interface in early pregnancy. Cell Mol Immunol. (2014) 11:438-48. doi: $10.1038 / \mathrm{cmi} .2014 .68$

54. Nancy P, Erlebacher A. Epigenetic repression of chemokine expression at the maternal-fetal interface as a mechanism of feto-maternal tolerance. Med Sci. (2012) 28:1037-9. doi: 10.1051/medsci/20122812005

55. Zlotnik A, Yoshie O. The chemokine superfamily revisited. Immunity. (2012) 36:705-12. doi: 10.1016/j.immuni.2012.05.008

56. Han J, Jeong W, Gu MJ, Yoo I, Yun CH, Kim J, et al. CysteineX-cysteine motif chemokine ligand 12 and its receptor CXCR4: Expression, regulation, and possible function at the maternalconceptus interface during early pregnancy in pigs. Biol Reprod. (2018) 99:1137-48. doi: 10.1093/biolre/ioy147

57. Złotkowska A, Andronowska A. Chemokines as the modulators of endometrial epithelial cells remodelling. Sci Rep. (2019) 9:14467. doi: 10.1038/s41598-019-49502-5

58. Złotkowska A, Andronowska A. Modulatory effect of chemokines on porcine endometrial stromal and endothelial cells. Domest Anim Endocrinol. (2020) 72:106475. doi: 10.1016/j.domaniend.2020.106475

59. Croy BA, Wessels JM, Linton NF, van den Heuvel M, Edwards AK, Tayade C. Cellular and molecular events in early and mid gestation porcine implantation sites: a review. Soc Reprod Fertil Suppl. (2009) 66:233-44. doi: 10.1530/biosciprocs. 18.0029

60. Engelhardt H, Croy BA, King GJ. Role of uterine immune cells in early pregnancy in pigs. J Reprod Fertil. (1997) 52:115-31.

61. Engelhardt H, Croy BA, King GJ. Conceptus influences the distribution of uterine leukocytes during early porcine pregnancy. Biol Reprod. (2002) 66:1875-80. doi: 10.1095/biolreprod66.6.1875

62. Moffett A, Loke C. Immunology of placentation in eutherian mammals. Nat Rev. (2006) 6:584-94. doi: 10.1038/nri1897

63. Engelhardt H, Croy BA, King GJ. Evaluation of natural killer cell recruitment to embryonic attachment sites during early porcine pregnancy. Biol Reprod. (2002) 66:1185-92. doi: 10.1095/biolreprod66.4.1185

64. Croy BA, Waterfield A, Wood W, King GJ. Normal murine and porcine embryos recruit NK cells to the uterus. Cell Immunol. (1988) 115:47180. doi: 10.1016/0008-8749(88)90199-2

65. Dimova T, Mihaylova A, Spassova P, Georgieva R. Superficial implantation in pigs is associated with decreased numbers and redistribution of endometrial NK-cell populations. Am J Reprod Immunol. (2008) 59:35969. doi: 10.1111/j.1600-0897.2007.00579.x

66. Hunt JS, Vassmer D, Ferguson TA, Miller L. Fas ligand is positioned in mouse uterus and placenta to prevent trafficking of activated leukocytes between the mother and the conceptus. J Immunol. (1997) 158:4122-8.
67. Runic R, Lockwood CJ, LaChapelle L, Dipasquale B, Demopoulos RI, Kumar A, et al. Apoptosis and Fas expression in human fetal membranes. J Clin Endocrinol Metab. (1998) 83:660-6. doi: 10.1210/jc.83.2.660

68. Trowsdale J, Betz AG. Mother's little helpers: mechanisms of maternal-fetal tolerance. Nat Immunol. (2006) 7:241-6. doi: 10.1038/ni1317

69. Ramsoondar JJ, Christopherson RJ, Guilbert LJ, Dixon WT, Ghahary A, Ellis S, et al. Lack of class I major histocompatibility antigens on trophoblast of periimplantation blastocysts and term placenta in the pig. Biol Reprod. (1999) 60:387-97. doi: 10.1095/biolreprod60.2.387

70. Joyce MM, Burghardt JR, Burghardt RC, Hooper RN, Bazer FW, Johnson GA. Uterine MHC class I molecules and beta 2-microglobulin are regulated by progesterone and conceptus interferons during pig pregnancy. J Immunol. (2008) 181:2494-505. doi: 10.4049/jimmunol.181.4.2494

71. Kim M, Seo H, Choi Y, Shim J, Bazer FW, Ka H. Swine leukocyte antigen-DQ expression and its regulation by interferongamma at the maternal-fetal interface in pigs. Biol Reprod. (2012) 86:43. doi: 10.1095/biolreprod.111.094011

72. Baltimore D, Boldin MP, O'Connell RM, Rao DS, Taganov KD. MicroRNAs: new regulators of immune cell development and function. Nat Immunol. (2008) 9:839-45. doi: 10.1038/ni.f.209

73. Taganov KD, Boldin MP, Baltimore D. MicroRNAs and immunity: tiny players in a big field. Immunity. (2007) 26:133-7. doi: 10.1016/j.immuni.2007.02.005

74. Chen K, Rajewsky N. The evolution of gene regulation by transcription factors and microRNAs. Nat Rev. (2007) 8:93-103. doi: 10.1038/nrg1990

75. Winn VD, Haimov-Kochman R, Paquet AC, Yang YJ, Madhusudhan MS, Gormley $\mathrm{M}$, et al. Gene expression profiling of the human maternalfetal interface reveals dramatic changes between midgestation and term. Endocrinology. (2007) 148:1059-79. doi: 10.1210/en.2006-0683

76. Krol J, Loedige I, Filipowicz W. The widespread regulation of microRNA biogenesis, function and decay: abstract: nature reviews genetics. Nat Rev Genet. (2010) 11:597-610. doi: 10.1038/nrg2843

77. Su L, Zhao S, Zhu M, Yu M. Differential expression of microRNAs in porcine placentas on Days 30 and 90 of gestation. Reprod Fertil Dev. (2010) 22:1175-82. doi: 10.1071/ RD10046

78. Su L, Liu R, Cheng W, Zhu M, Li X, Zhao S, et al. Expression patterns of microRNAs in porcine endometrium and their potential roles in embryo implantation and placentation. PLoS ONE. (2014) 9:e87867. doi: 10.1371/journal.pone.0087867

79. Krawczynski K, Bauersachs S, Reliszko ZP, Graf A, Kaczmarek MM. Expression of microRNAs and isomiRs in the porcine endometrium: implications for gene regulation at the maternal-conceptus interface. $B M C$ Genom. (2015) 16:906. doi: 10.1186/s12864-015-2172-2

80. Stowe HM, Curry E, Calcatera SM, Krisher RL, Paczkowski M, Pratt SL. Cloning and expression of porcine Dicer and the impact of developmental stage and culture conditions on MicroRNA expression in porcine embryos. Gene. (2012) 501:198-205. doi: 10.1016/j.gene.201 2.03.058

81. Córdoba S, Balcells I, Castelló A, Ovilo C, Noguera JL, Timoneda $\mathrm{O}$, et al. Endometrial gene expression profile of pregnant sows with extreme phenotypes for reproductive efficiency. Sci Rep. (2015) 5:14416. doi: 10.1038/srep14416

82. Huang L, Yin ZJ, Feng YF, Zhang XD, Wu T, Ding YY, et al. Identification and differential expression of microRNAs in the ovaries of pigs (Sus scrofa) with high and low litter sizes. Anim Genet. (2016) 47:54351. doi: 10.1111/age.12452

83. Lei B, Gao S, Luo LF, Xia XY, Jiang SW, Deng CY, et al. A SNP in the miR-27a gene is associated with litter size in pigs. Mol Biol Rep. (2011) 38:3725-9. doi: 10.1007/s11033-010-0487-2

84. Liu R, Wang M, Su L, Li X, Zhao S, Yu M. The expression pattern of microRNAs and the associated pathways involved in the development of porcine placental folds that contribute to the expansion of the exchange surface area. Biol Reprod. (2015) 93:62. doi: 10.1095/biolreprod.114.126540

85. Wessels JMJM, Edwards AKAK, Khalaj K, Kridli RTRT, Bidarimath M, Tayade C. The microRNAome of pregnancy: deciphering miRNA networks at the maternal-fetal interface. PLOS ONE. (2013) 8:e72264. doi: 10.1371/journal.pone.007 
86. Van Niel G, D’Angelo G, Raposo G. Shedding light on the cell biology of extracellular vesicles. Nat Rev Mol Cell Biol. (2018) 19:21328. doi: 10.1038/nrm.2017.125

87. Zhao G, Yang C, Yang J, Liu $\mathrm{P}$, Jiang $\mathrm{K}$, Shaukat $\mathrm{A}$, et al. Placental exosome-mediated Bta-miR-499-Lin28B/let-7 axis regulates inflammatory bias during early pregnancy. Cell Death Dis. (2018) 9:704. doi: 10.1038/s41419-018-0713-8

88. Shao H, Chung J, Balaj L, Charest A, Bigner DD, Carter BS, et al. Protein typing of circulating microvesicles allows real-time monitoring of glioblastoma therapy. Nat Med. (2012) 18:1835-40. doi: 10.1038/nm.2994

89. Théry C, Witwer KW, Aikawa E, Alcaraz MJ, Anderson JD, Andriantsitohaina R, et al. Minimal information for studies of extracellular vesicles 2018 (MISEV2018): a position statement of the International Society for Extracellular Vesicles and update of the MISEV2014 guidelines. $J$ Extracell Vesicles. (2018) 7:1535750. doi: 10.1080/20013078.2018.1461450

90. Willms E, Johansson HJ, Mäger I, Lee Y, Blomberg KEM, Sadik M, et al. Cells release subpopulations of exosomes with distinct molecular and biological properties. Sci Rep. (2016) 6:22519. doi: 10.1038/srep22519

91. Baietti MF, Zhang Z, Mortier E, Melchior A, Degeest G, Geeraerts A, et al. Syndecan-syntenin-ALIX regulates the biogenesis of exosomes. Nat Cell Biol. (2012) 14:677-85. doi: 10.1038/ncb2502

92. Villarroya-Beltri C, Baixauli F, Gutiérrez-Vázquez C, Sánchez-Madrid F, Mittelbrunn M. Sorting it out: regulation of exosome loading. Semin Cancer Biol. (2014) 28:3-13. doi: 10.1016/j.semcancer.2014.04.009

93. Villarroya-Beltri C, Baixauli F, Mittelbrunn M, Fernández-Delgado I, Torralba D, Moreno-Gonzalo O, et al. ISGylation controls exosome secretion by promoting lysosomal degradation of MVB proteins. Nat Commun. (2016) 7:13588. doi: $10.1038 /$ ncomms 13588

94. Hoshino D, Kirkbride KC, Costello K, Clark ES, Sinha S, Grega-Larson N, et al. Exosome secretion is enhanced by invadopodia and drives invasive behavior. Cell Rep. (2013) 5:1159-68. doi: 10.1016/j.celrep.2013.10.050

95. Hessvik NP, Llorente A. Current knowledge on exosome biogenesis and release. Cell Mol Life Sci. (2018) 75:193-208. doi: 10.1007/s00018-017-2595-9

96. Jahn R, Scheller RH. SNAREs - engines for membrane fusion. Nat Rev Mol Cell Biol. (2006) 7:631-43. doi: 10.1038/nrm2002

97. Pfeffer SR. Unsolved mysteries in membrane traffic. Annu Rev Biochem. (2007) 76:629-45. doi: 10.1146/annurev.biochem.76.061705.130002

98. Gross JC, Chaudhary V, Bartscherer K, Boutros M. Active Wnt proteins are secreted on exosomes. Nat Cell Biol. (2012) 14:1036-45. doi: 10.1038/ncb2574

99. Ruiz-Martinez M, Navarro A, Marrades RM, Viñolas N, Santasusagna S, Muñoz C, et al. YKT6 expression, exosome release, and survival in non-small cell lung cancer. Oncotarget. (2016) 7:51515-24. doi: 10.18632/oncotarget.9862

100. Koles K, Budnik V. Exosomes go with the Wnt. Cell Logist. (2012) 2:16973. doi: $10.4161 / \mathrm{cl} .21981$

101. Hyenne V, Apaydin A, Rodriguez D, Spiegelhalter C, Hoff-Yoessle S, Diem $\mathrm{M}$, et al. RAL-1 controls multivesicular body biogenesis and exosome secretion. J Cell Biol. (2015) 211:27-37. doi: 10.1083/jcb.201504136

102. Yáñez-Mó M, Siljander PRM, Andreu Z, Zavec AB, Borràs FE, Buzas EI, et al. Biological properties of extracellular vesicles and their physiological functions. J Extracell Vesicles. (2015) 4:1-60. doi: 10.3402/jev.v4.27066

103. Mathivanan S, Ji H, Simpson RJ. Exosomes: extracellular organelles important in intercellular communication. J Proteom. (2010) 73:190720. doi: 10.1016/j.jprot.2010.06.006

104. Camussi G, Deregibus MC, Bruno S, Cantaluppi V, Biancone L. Exosomes/microvesicles as a mechanism of cell-to-cell communication. Kidney Int. (2010) 78:838-48. doi: 10.1038/ki.2010.278

105. Morelli AE, Larregina AT, Shufesky WJ, Sullivan MLG, Stolz DB, Papworth GD, et al. Endocytosis, intracellular sorting, and processing of exosomes by dendritic cells. Blood. (2004) 104:3257-66. doi: 10.1182/blood-2004-03-0824

106. Kamerkar S, Lebleu VS, Sugimoto H, Yang S, Ruivo CF, Melo SA, et al. Exosomes facilitate therapeutic targeting of oncogenic KRAS in pancreatic cancer. Nature. (2017) 546:498-503. doi: 10.1038/nature22341

107. Ratajczak J, Miekus K, Kucia M, Zhang J, Reca R, Dvorak P, et al. Embryonic stem cell-derived microvesicles reprogram hematopoietic progenitors: evidence for horizontal transfer of mRNA and protein delivery. Leukemia. (2006) 20:847-56. doi: 10.1038/sj.leu.2404132
108. Valadi H, Ekstrom K, Bossios A, Sjostrand M, Lee JJ, Lotvall JO, et al. Exosome-mediated transfer of mRNAs and microRNAs is a novel mechanism of genetic exchange between cells. Nat Cell Biol. (2007) 9:6549. doi: $10.1038 /$ ncb1596

109. Mittelbrunn M, Sánchez-Madrid F. Intercellular communication: diverse structures for exchange of genetic information. Nat Rev Mol Cell Biol. (2012) 13:328-35. doi: 10.1038/nrm3335

110. Scherjon S, Lashley L, van der Hoorn ML, Claas F. Fetus specific T cell modulation during fertilization, implantation and pregnancy. Placenta. (2011) 32(Suppl.4):S291-7. doi: 10.1016/j.placenta.2011.03.014

111. Mitchell MD, Peiris HN, Kobayashi M, Koh YQ, Duncombe G, Illanes SE, et al. Placental exosomes in normal and complicated pregnancy. Am J Obstet Gynecol. (2015) 213:S173-81. doi: 10.1016/j.ajog.2015.07.001

112. Luo S-SS, Ishibashi O, Ishikawa G, Ishikawa T, Katayama A, Mishima $\mathrm{T}$, et al. Human villous trophoblasts express and secrete placenta-specific microRNAs into maternal circulation via exosomes. Biol Reprod. (2009) 81:717-29. doi: 10.1095/biolreprod.108.075481

113. Ng YH, Rome S, Jalabert A, Forterre A, Singh H, Hincks CL, et al. Endometrial exosomes/microvesicles in the uterine microenvironment: a new paradigm for embryo-endometrial cross talk at implantation. PLoS ONE. (2013) 8:e58502. doi: 10.1371/journal.pone.0058502

114. Sokolova V, Ludwig A-K, Hornung S, Rotan O, Horn PA, Epple M, et al. Characterisation of exosomes derived from human cells by nanoparticle tracking analysis and scanning electron microscopy. Colloids Surf B Biointerfaces. (2011) 87:146-50. doi: 10.1016/j.colsurfb.2011.05.013

115. Gurung S, Greening DW, Catt S, Salamonsen L, Evans J. Exosomes and soluble secretome from hormone-treated endometrial epithelial cells direct embryo implantation. Mol Hum Reprod. (2020) 26:51020. doi: $10.1093 / \mathrm{moleh} /$ gaaa034

116. Alcântara-Neto AS, Fernandez-Rufete M, Corbin E, Tsikis G, Uzbekov R, Garanina AS, et al. Oviduct fluid extracellular vesicles regulate polyspermy during porcine in vitro fertilisation. Reprod Fertil Dev. (2019) 32:40918. doi: 10.1071/RD19058

117. da Silveira JC, Veeramachaneni DNR, Winger QA, Carnevale EM, Bouma GJ. Cell-secreted vesicles in equine ovarian follicular fluid contain mirnas and proteins: a possible new form of cell communication within the ovarian follicle. Biol Reprod. (2012) 86:71. doi: 10.1095/biolreprod.111.093252

118. Ogawa Y, Miura Y, Harazono A, Kanai-Azuma M, Akimoto Y, Kawakami H, et al. Proteomic analysis of two types of exosomes in human whole saliva. Biol Pharm Bull. (2011) 34:13-23. doi: 10.1248/bpb.34.13

119. Caby M-P, Lankar D, Vincendeau-Scherrer C, Raposo G, Bonnerot C. Exosomal-like vesicles are present in human blood plasma. Int Immunol. (2005) 17:879-87. doi: 10.1093/intimm/dxh267

120. Chen T, Xi QY, Ye RS, Cheng X, Qi QE, Wang SB, et al. Exploration of microRNAs in porcine milk exosomes. BMC Genom. (2014) 15:100. doi: 10.1186/1471-2164-15-100

121. Keller S, Rupp C, Stoeck A, Runz S, Fogel M, Lugert S, et al. CD24 is a marker of exosomes secreted into urine and amniotic fluid. Kidney Int. (2007) 72:1095-102. doi: 10.1038/sj.ki.5002486

122. Barranco I, Padilla L, Parrilla I, Álvarez-Barrientos A, Pérez-Patiño C, Peña FJ, et al. Extracellular vesicles isolated from porcine seminal plasma exhibit different tetraspanin expression profiles. Sci Rep. (2019) 9:11584. doi: 10.1038/s41598-019-48095-3

123. Pisitkun T, Shen R-F, Knepper MA. Identification and proteomic profiling of exosomes in human urine. Proc Natl Acad Sci USA. (2004) 101:13368-73. doi: 10.1073/pnas.040345 3101

124. Aliotta JM, Pereira M, Johnson KW, de Paz N, Dooner MS, Puente N, et al. Microvesicle entry into marrow cells mediates tissue-specific changes in mRNA by direct delivery of mRNA and induction of transcription. Exp Hematol. (2010) 38:233-45. doi: 10.1016/j.exphem.2010.01.002

125. Hergenreider E, Heydt S, Tréguer K, Boettger T, Horrevoets AJG, Zeiher $\mathrm{AM}$, et al. Atheroprotective communication between endothelial cells and smooth muscle cells through miRNAs. Nat Cell Biol. (2012) 14:24956. doi: $10.1038 / \mathrm{ncb} 2441$

126. Segura E, Guerin C, Hogg N, Amigorena S, Thery C, Guérin C, et al. CD8+ dendritic cells use LFA-1 to capture MHC-peptide complexes from exosomes in vivo. J Immunol. (2007) 179:1489-96. doi: 10.4049/jimmunol.179.3.1489 
127. Mincheva-Nilsson L, Baranov V. The role of placental exosomes in reproduction. Am J Reprod Immunol. (2010) 63:520-33. doi: 10.1111/j.1600-0897.2010.00822.x

128. Salomon C, Torres MJ, Kobayashi M, Scholz-Romero K, Sobrevia L, Dobierzewska A, et al. A gestational profile of placental exosomes in maternal plasma and their effects on endothelial cell migration. PLoS ONE. (2014) 9:e98667. doi: 10.1371/journal.pone.0098667

129. Delorme-Axford E, Donker RB, Mouillet J-FF, Chu T, Bayer A, Ouyang Y, et al. Human placental trophoblasts confer viral resistance to recipient cells. Proc Natl Acad Sci USA. (2013) 110:12048-53. doi: 10.1073/pnas. 1304718110

130. Kshirsagar SK, Alam SM, Jasti S, Hodes H, Nauser T, Gilliam $\mathrm{M}$, et al. Immunomodulatory molecules are released from the first trimester and term placenta via exosomes. Placenta. (2012) 33:982-90. doi: 10.1016/j.placenta.2012.10.005

131. Clifton VL, Stark MJ, Osei-Kumah A, Hodyl NA. Review: the feto-placental unit, pregnancy pathology and impact on long term maternal health. Placenta. 5:S37-41. doi: 10.1016/j.placenta.2011.11.005

132. Germain SJ, Sacks GP, Sooranna SR, Soorana SR, Sargent IL, Redman CW. Systemic inflammatory priming in normal pregnancy and preeclampsia: the role of circulating syncytiotrophoblast microparticles. J Immunol. (2007) 178:5949-56. doi: 10.4049/jimmunol.178.9.5949

133. Southcombe J, Tannetta D, Redman C, Sargent I. The immunomodulatory role of syncytiotrophoblast microvesicles. PLoS ONE. (2011) 6:e20245. doi: 10.1371/journal.pone.0020245

134. Jacobson MD, Weil M, Raff MC. Programmed cell death in animal development. Cell. (1997) 88:347-54. doi: 10.1016/S0092-8674(00)81873-5

135. Stenqvist A-C, Nagaeva O, Baranov V, Mincheva-Nilsson L. Exosomes secreted by human placenta carry functional fas ligand and TRAIL molecules and convey apoptosis in activated immune cells, suggesting exosomemediated immune privilege of the fetus. I Immunol. (2013) 191:551523. doi: 10.4049/jimmunol.1301885

136. Nakamura K, Kusama K, Bai R, Sakurai T, Isuzugawa K, Godkin $\mathrm{JD}$, et al. Induction of IFNT-stimulated genes by conceptusderived exosomes during the attachment period. PLoS ONE. (2016) 11:e0158278. doi: 10.1371/journal.pone.0158278

137. Kusama K, Nakamura K, Bai R, Nagaoka K, Sakurai T, Imakawa K. Intrauterine exosomes are required for bovine conceptus implantation. Biochem Biophys Res Commun. (2018) 495:1370-5. doi: 10.1016/j.bbrc.2017.11.176

138. Hua R, Wang Y, Lian W, Li W, Xi Y, Xue S, et al. Small RNA-seq analysis of extracellular vesicles from porcine uterine flushing fluids during periimplantation. Gene. (2021) 766:145117. doi: 10.1016/j.gene.2020.145117

139. Bai R, Bai H, Kuse M, Ideta A, Aoyagi $Y$, Fujiwara $H$, et al. Involvement of VCAM1 in the bovine conceptus adhesion to the uterine endometrium. Reproduction. (2014) 148:119-27. doi: 10.1530/REP-13-0655

140. Greening DW, Nguyen HPTT, Elgass K, Simpson RJ, Salamonsen LA. Human endometrial exosomes contain hormone-specific cargo modulating trophoblast adhesive capacity: insights into endometrial-embryo interactions. Biol Reprod. (2016) 94:38. doi: 10.1095/biolreprod.115.134890

141. Dantzer V, Leiser R. Initial vascularisation in the pig placenta: I. Demonstration of nonglandular areas by histology and corrosion casts. Anat Rec. (1994) 238:177-90. doi: 10.1002/ar.1092380204

142. Leiser R, Dantzer V. Initial vascularisation in the pig placenta: II. Demonstration of gland and areola-gland subunits by histology and corrosion casts. Anat Rec. (1994) 238:326-34. doi: 10.1002/ar.1092380307
143. Giacomini E, Alleva E, Fornelli G, Quartucci A, Privitera L, Vanni VS, et al. Embryonic extracellular vesicles as informers to the immune cells at the maternal-fetal interface. Clin Exp Immunol. (2019) 198:1523. doi: $10.1111 /$ cei.13304

144. Nakamura K, Kusama K, Ideta A, Kimura K, Hori M, Imakawa K. Effects of miR-98 in intrauterine extracellular vesicles on maternal immune regulation during the peri-implantation period in cattle. Sci Rep. (2019) 9:20330. doi: 10.1038/s41598-019-56879-w

145. Zhou C, Cai G, Meng F, Xu Z, He Y, Hu Q, et al. Deep-sequencing identification of MicroRNA biomarkers in serum exosomes for early pig pregnancy. Front Genet. (2020) 11:536. doi: 10.3389/fgene.2020.00536

146. Pohler KG, Green JA, Moley LA, Gunewardena S, Hung WT, Payton RR, et al. Circulating microRNA as candidates for early embryonic viability in cattle. Mol Reprod Dev. (2017) 84:731-43. doi: 10.1002/mrd.22856

147. De Bem THC, Da Silveira JC, Sampaio RV, Sangalli JR, Oliveira MLF, Ferreira RM, et al. Low levels of exosomal-miRNAs in maternal blood are associated with early pregnancy loss in cloned cattle. Sci Rep. (2017) 7:14319. doi: 10.1038/s41598-017-14616-1

148. Done SH, Paton DJ. Porcine reproductive and respiratory syndrome: clinical disease, pathology and immunosuppression. Vet Rec. (1995)136:325. doi: 10.1136/vr.136.2.32

149. Montaner-Tarbes S, Borrás FE, Montoya M, Fraile L, Del Portillo HA. Serumderived exosomes from non-viremic animals previously exposed to the porcine respiratory and reproductive virus contain antigenic viral proteins. Vet Res. (2016) 47:59. doi: 10.1186/s13567-016-0345-x

150. Wang T, Fang L, Zhao F, Wang D, Xiao S. Exosomes mediate intercellular transmission of porcine reproductive and respiratory syndrome virus (PRRSV). J Virol. (2017) 92:e01734-17. doi: 10.1128/JVI.01734-17

151. Zhu L, Song H, Zhang X, Xia X, Sun H. Inhibition of porcine reproductive and respiratory syndrome virus infection by recombinant adenovirus- and/or exosome-delivered the artificial microRNAs targeting sialoadhesin and CD163 receptors. Virol J. (2014) 11:225. doi: 10.1186/s12985-014-0225-9

152. Zhu L, Bao L, Zhang X, Xia X, Sun H. Inhibition of porcine reproductive and respiratory syndrome virus replication with exosome-transferred artificial microRNA targeting the 3' untranslated region. J Virol Methods. (2015) 223:61-8. doi: 10.1016/j.jviromet.2015.07.018

153. Montaner-Tarbes S, Novell E, Tarancón V, Borrás FE, Montoya M, Fraile L, et al. Targeted-pig trial on safety and immunogenicity of serum-derived extracellular vesicles enriched fractions obtained from Porcine Respiratory and Reproductive virus infections. Sci Rep. (2018) 8:17487. doi: 10.1038/s41598-018-3 6141-5

Conflict of Interest: The authors declare that the research was conducted in the absence of any commercial or financial relationships that could be construed as a potential conflict of interest.

Copyright (c) 2021 Bidarimath, Lingegowda, Miller, Koti and Tayade. This is an open-access article distributed under the terms of the Creative Commons Attribution License (CC BY). The use, distribution or reproduction in other forums is permitted, provided the original author(s) and the copyright owner(s) are credited and that the original publication in this journal is cited, in accordance with accepted academic practice. No use, distribution or reproduction is permitted which does not comply with these terms. 